\title{
Systematic Evaluation of the Advantages of Static Shoulder FSW for Joining Aluminium
}

DOI:

10.4028/www.scientific.net/MSF.794-796.407

\section{Document Version}

Accepted author manuscript

Link to publication record in Manchester Research Explorer

\section{Citation for published version (APA):}

Wu, H., Chen, Y. C., Strong, D., \& Prangnell, P. (2014). Systematic Evaluation of the Advantages of Static Shoulder FSW for Joining Aluminium. Materials Science Forum, 794, 407-412.

https://doi.org/10.4028/www.scientific.net/MSF.794-796.407

\section{Published in:}

Materials Science Forum

\section{Citing this paper}

Please note that where the full-text provided on Manchester Research Explorer is the Author Accepted Manuscript or Proof version this may differ from the final Published version. If citing, it is advised that you check and use the publisher's definitive version.

\section{General rights}

Copyright and moral rights for the publications made accessible in the Research Explorer are retained by the authors and/or other copyright owners and it is a condition of accessing publications that users recognise and abide by the legal requirements associated with these rights.

\section{Takedown policy}

If you believe that this document breaches copyright please refer to the University of Manchester's Takedown Procedures [http://man.ac.uk/04Y6Bo] or contact uml.scholarlycommunications@manchester.ac.uk providing relevant details, so we can investigate your claim.

\section{OPEN ACCESS}




\title{
Systematic Evaluation of the Advantages of Static Shoulder FSW for Joining Aluminium
}

\author{
Hao $\mathrm{Wu}^{1 \mathrm{a}}$, Ying-Chun Chen ${ }^{1 \mathrm{~b}}$, David Strong ${ }^{1 \mathrm{c}}$ and Phil Prangnell ${ }^{1 \mathrm{~d}}$ \\ ${ }^{1}$ School of Materials, Univ. of Manchester, Manchester M13 9PL, UK \\ ahao.wu-5@postgrad.manchester.ac.uk, byingchun.chen@manchester.ac.uk, \\ 'david.strong@manchester.ac.uk, ${ }^{\mathrm{d}}$ philip.prangnell@manchester.ac.uk.
}

Keywords: Friction Stir Welding, Stationary Shoulder, AA7050, Thermal Modelling, Distortion

\begin{abstract}
Static Shoulder Friction Stir Welding (SS-FSW) is a modification to conventional FSW that was originally developed to improve the weldability of titanium alloys by reducing through thickness temperature gradients. Surprisingly, to date, there have been no published systematic studies comparing SS-FSW to FSW for aluminium welding. This may be because the high conductivity of aluminium means the heat input produced by the shoulder is thought to be beneficial. In the work presented when welding a high strength 7050 aluminium alloy, even in a relatively thin $6 \mathrm{~mm}$ plate, it is shown that SS-FSW has several advantages; including a reduction in the heat input, a massive improvement in surface quality, and a more uniform through thickness temperature distribution, which leads to narrower welds with a reduced heat affected zone width and more homogeneous through thickness properties. The reasons for these benefits are discussed.
\end{abstract}

\section{Introduction}

Conventional Friction Stir Welding (FSW), which uses a solid tool comprised of a shoulder and pin that rotate at the same rate, is a well-established process that is now widely used to join aluminium generally with excellent results [1]. The process is particularly well suited to welding high strength aluminium aerospace alloys that suffer from solidification cracking in fusion processes and is therefore of considerable interest to the aerospace industry [1]. FSW was original developed in the UK by the TWI [1] and involves translating a rotating tool along the join line between two butted plates, which forges the weld members together without melting. Static, or Stationary, Shoulder Friction Stir Welding (SS-FSW) is a modification to the original process that was developed more recently to improve the weldability of titanium alloys $[2,3]$ where the low thermal conductivity of titanium results in the rotating tool shoulder creating a severe temperature gradient through the plate thickness [2]. This is because in conventional FSW between $60-80 \%$ of the heat is generated by the shoulder, which has the highest radial velocity. As the heat input is limited by melting at the contact surface, with thicker gauges, or lower conductivity materials, it is thus difficult to maintain a high enough temperature at the base of the weld to avoid pin failures without resorting to a low travel speed. Therefore, in principle when welding thicker aluminium plate the SS-FSW process should be advantageous, provided enough heat can be generated by the probe alone to off-set the higher conductivity of aluminium.

There are also several additional potential benefits of SS-FSW over conventional FSW, such as an improved surface finish [2] and a narrower temperature distribution that is more parallel through the thickness, which could lead to a reduced heat affected zone width, as well as lower levels of distortion. It has also been shown in one rare study, using a AA6061 alloy, that with a static shoulder the texture in the weld zone becomes dominated by the pin [3]. However, perhaps surprisingly, there is no work published in the literature that directly compares the two processes and allows a consensus to be reached on the preferred welding method. This may be partly because 
with a conventional tool the power generated by the pin at a fixed rpm is typically only $20-30 \%$ of that of the tool shoulder [4,5], so that the same welding conditions are not appropriate for both processes and it is therefore not obvious how to systematically compare the two techniques.

Here, we report on a preliminary investigation where we have attempted to fill this knowledge gap by systematically comparing the two processes when welding a typical Al-aerospace alloy (AA7050). To achieve this end, we have used an identical shoulder and pin geometry for each method and first assessed the relationship between the heat input and the welding parameters, so that both processes could be compared using their optimum welding conditions. The welds were performed in relatively thin $6 \mathrm{~mm}$ plate where it might be thought that stationary shoulder would offer less benefit. Modelling has also been used to fit the thermal field for each process and predict the effect on the HAZ shape. We have also measured the surface finish and note a new type of weld defect caused by over-heating that is specific to the SS-FSW process.

\section{Experimental}

All the welds in this study were produced in $6.3 \mathrm{~mm}$ thick AA7050-T7651 plate with a butt configuration, using conventional and stationery shoulder tools that had identical geometry. Both tools had a shoulder diameter of $18 \mathrm{~mm}$ and a $5.9 \mathrm{~mm}$ long conical, threaded, tri-flat probe $(6.2 \mathrm{~mm}$ and $4 \mathrm{~mm}$ diameter at the root and tip, respectively). The standard FSW tool had a concave shoulder and welding was performed with a $2^{\circ}$ tilt and plunge depth of $0.2 \mathrm{~mm}$. With the SS-FSW tool the shoulder was fixed to the welding head and the pin rotated within the static shoulder. The tool was vertical and the shoulder had a slight convex radius to allow it to slide. With both processes a parametric study was first performed to measure torque decay curves with increasing rotation rate, [5,6] (see below). The torque (M) and welding forces were logged from the machine. A finite difference model was used to fit the welds' thermal field's, using a surface ring shaped heat source, to represent the shoulder, and ten increasing diameter cylindrical volume sources to represent the conical probe. The power was distributed in each case in proportion to the surface velocity. For the stationary shoulder the shoulder power was set to zero. Thermocouple measurements were made at six locations; near the top surface, plate centre and bottom, near the tool, and at distances of 10, 20, $30 \mathrm{~mm}$, at the plate centre line to provide calibration data for the thermal model.

To analyse the resultant welds hardness maps were produced across weld transverse cross sections using an Instron microhardness machine with a $0.5 \mathrm{~kg}$ load and microstructural features were investigated by conventional optical microscopy. A $\mu$-scan SC200 laser profiler was used to compare the surface roughness obtained by the two techniques.

\section{Results and Discussion}

In FSW the welding power, Q, can be related to the torque, M, by;

$$
\mathrm{Q}=\mathrm{M} \omega,
$$

where $\omega$ is the rotation rate $\left(\mathrm{rad} \mathrm{s}^{-1}\right)$ [4]. If a uniform material flow stress across the tool surfaces is assumed a simple analytical model, adapted for a tapered pin from ref [4], can be expressed as:

$$
M=2 \pi \frac{\sigma}{\sqrt{3}}\left[\frac{1}{3}\left(1-\delta_{1}\right)\left(r_{s}^{3}-r_{p t}{ }^{3}\right)+\left(\frac{1}{3} m^{2} h^{3}+m h^{2} r_{p b}+h r_{p b}^{2}\right)+\frac{1}{3} r_{p b}^{3}\right]
$$

where the first term represents the contribution from the shoulder, the second the probe conical surface, and the third the probe base. The tool dimensions $r_{s}, r_{p t}, r_{p b}$, and $h$ are the shoulder, probe root, and tip radii, and probe height respectively, $m$ is the taper gradient of the probe, $\sigma$ is the materials flow stress, and $\delta$ is a slip parameter. This relationship can be used to calculate the theoretical difference in heat generated between the FSW and SS-FSW tools at a given rotation rate 
which with the tool geometry used is $\sim 6: 1$. By calculating the theoretical torque at zero rpm, when the material will be at room temperature and have a uniform flow stress, a zero point can be obtained allowing exponential torque - rotation rate decay curves to be fitted to the experimental data [6] (Fig. 1a), from which the welding power curve can also be derived (Fig. 1b).

As has been previously noted [5,6] there is a smaller dependence on the travel speed and the torque is dominated by the rotation rate. In agreement with the calculation given above, the fitted torque decay curves show, unsurprisingly, that for a given rotation rate the static shoulder tool developed a much lower torque, and hence welding power, than the standard FSW process, with approximately $70 \%$ of the power being provided by the shoulder at low rpm, but this difference reduced to about $50 \%$ at high $\mathrm{rpm}$ where the torque reaches a lower limit.
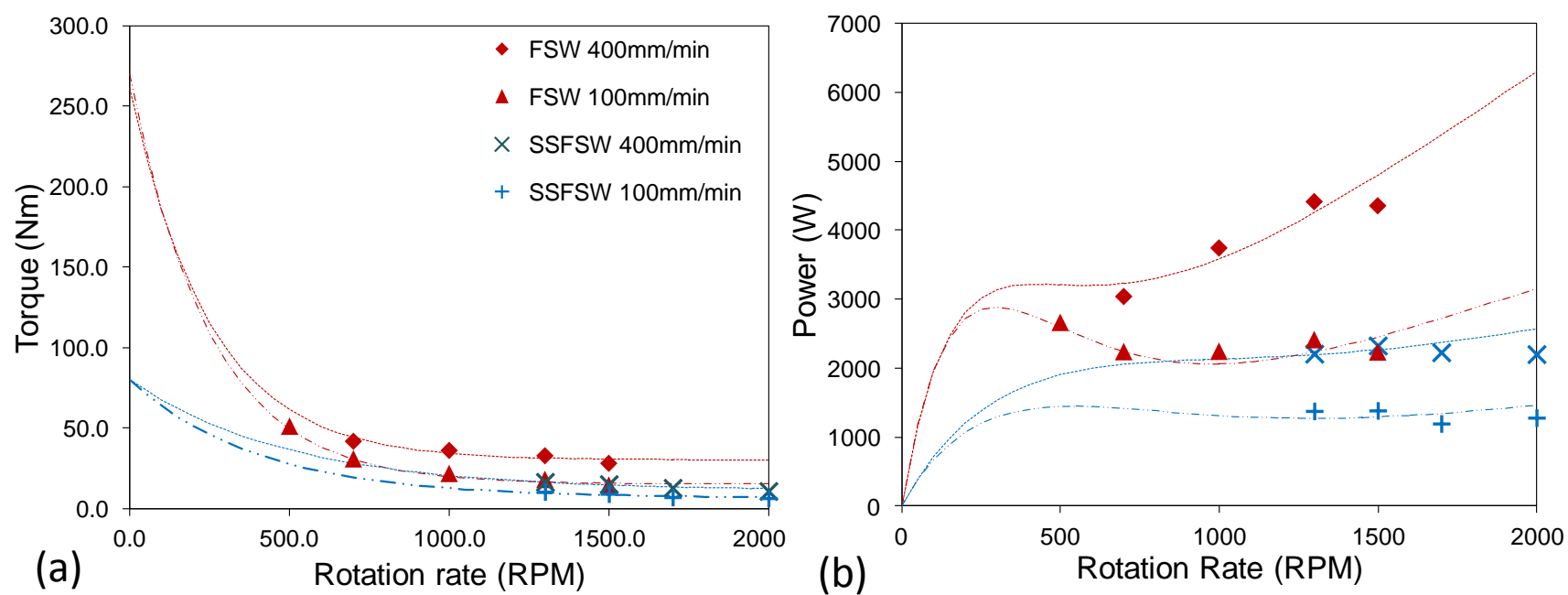

Fig. 1 (a) Fitted torque - rotation rate decay curves for the FSW and SS-FSW processes and (b) the corresponding welding power curves.

From Fig. 1 it is immediately apparent that it is not sensible to compare FSW to static shoulder welding with the same welding parameters because this produces very different heat inputs that are not necessarily optimised for each process: i.e. welds produced at the same travel speed will not have the same optimum rotation rate, owing to the different tool surface velocities and surface areas. It was also not possible to compare the two techniques on the basis of the same welding power at the same travel speed, because welding with as low a power as SS-FSW with the FSW process was not possible without pin failures, due to the much lower RPM necessary, which resulted in the material at the base of the weld becoming too cold and creating an excessive load on the pin. To compare the two processes, welding conditions were therefore selected that gave as close a heat input as possible at the same high travel speed of $400 \mathrm{~mm} \mathrm{~min}^{-1}$, while maintaining tool life. Thus, 1500 RPM and 700 RPM were selected for the SS-FSW and FSW respectively, which resulted in a $\sim 30 \%$ lower welding power for the SS-FSW tool, at the same travel speed.

Surface finish A potential advantage of static shoulder welding is the superior surface finish it can produce relative to FSW [2]. In the present study this was investigated using a $\mu$-scan SC200 laser profile; typical results from which are shown in Fig. 2. For SS-FSW, the surface roughness was reduced by over an order of magnitude compared to that with FSW with a rotating shoulder. In addition, the overall depression of the surface caused by the shoulder plunge required to make a defect free weld was also substantially reduced to only $0.02 \mathrm{~mm}$ for SS-FSW, compared to $0.6 \mathrm{~mm}$ for the standard tool. The far smoother surface results from the ironing effect generated by the static shoulder, which with aluminium gives a comparable finish to that obtained from a polished extrusion die. The lack of tool plunge and depression of the surface is also an important benefit and arises because the down-force of the static shoulder is supported by the colder surrounding plate allowing as high a pressure to be generated as in FSW without the tool sinking into the plate 
surface. However, a disadvantage of the stationary shoulder approach was noted in this study, in that surface cracking was observed with too high tool heat inputs and, in particular travel speeds. (Fig. 3). These flaws are similar to speed cackling seen in extruding aluminium alloys with a wide freezing range [6], and occur due to a combination of sticking to the die surface and grain boundary tearing when the material becomes over heated.
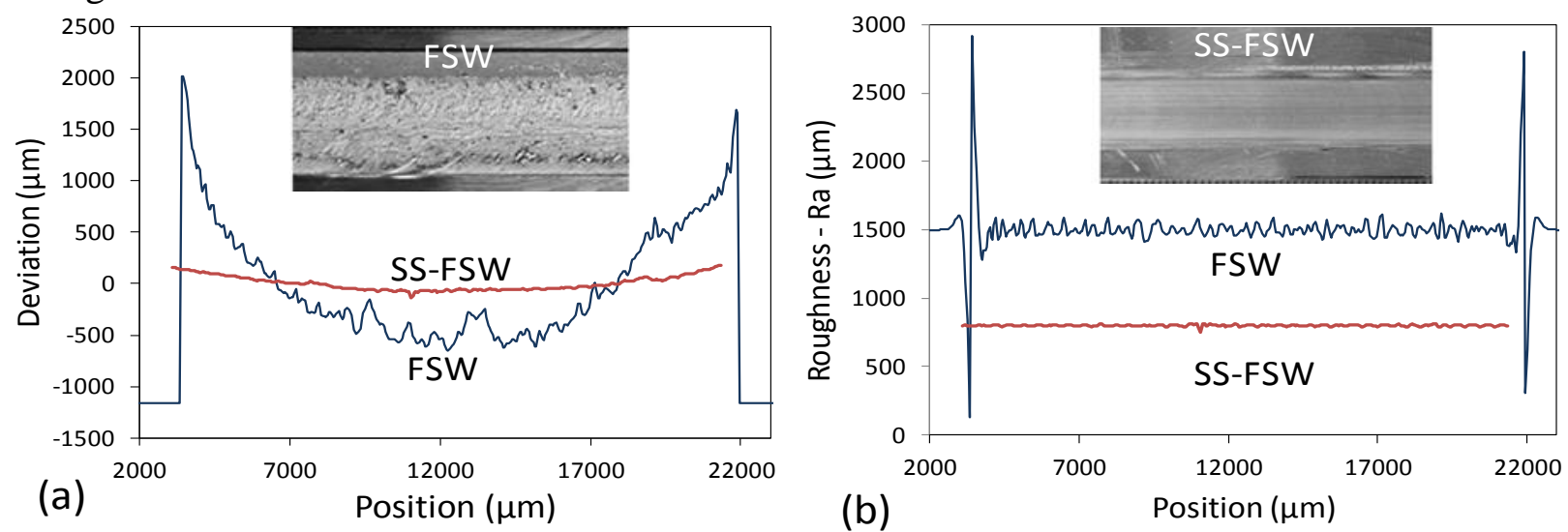

Fig. 2 The effect of SS-FSW on roughness showing laser surface height profiles for (a) FSW and (b) SS-FSW and (c) averaged profiles across both welds produced under optimum conditions.

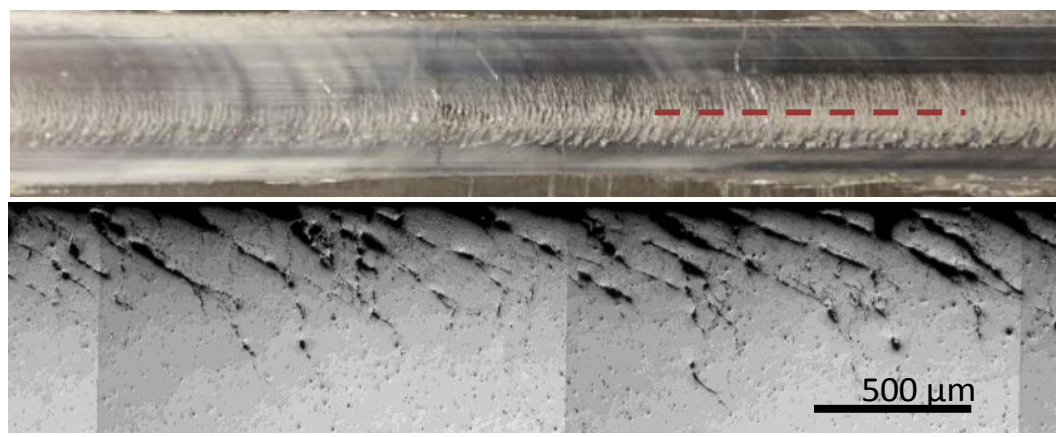

Fig. 3 Surface speed cackling seen in the SS-FSW process at $2000 \mathrm{rpm}$ and $400 \mathrm{~mm} \mathrm{~min}^{-1}$.

Thermal Field Simulation. The thermal model was used to investigate the effect of systematically reducing the heat input from the shoulder in FSW to zero, as is the case in static shoulder welding (Fig. 3). Modelling was carried out by first fitting the thermal field to temperature measurements for the FSW and SS-FSW processes and then progressively reducing the shoulder power from the FSW case to zero for SS-FSW for two probe conditions; i) while maintaining a constant probe power and ii) where the probe power was increased (i.e. as would be the case for increasing the rotation rate) to maintain the same temperature at the base of the weld of $450^{\circ} \mathrm{C}$. Although the model is relatively simple, it can be seen from Fig. 4 that it illustrates the trends expected and agrees well with the hardness maps in Fig. 5. In both scenarios, by reducing the heat input contribution from the shoulder, the thermal field becomes narrower and more parallel through thickness. However, when the probe power is kept constant the weld rapidly becomes too cold. In comparison, if the probe power is increased to compensate for the loss of the shoulder rotation it is evident that the thermal field still becomes narrower at the top of the weld and more uniform through the plate thickness.

Weld Zone Profile. The hardness distribution across FSW weld zones in heat-treatable Al-alloys is dominated by the state of matrix precipitation, which is largely controlled by the local thermal cycle $[8,9]$. Generally there are two competing effects that govern the local hardness; softening caused by coarsening, transformation and dissolution of strengthening phases, and post weld natural ageing. In alloys like AA7050 post weld natural ageing can recover much of the strength lost if the local temperature exceeded the alloys solvus temperature [8,9]. This normally leads to a ' $\mathrm{W}$ ' shaped hardness profile, where the centre of the nugget zone is hot enough to become solutionised and the 
hardness minima correspond to the positions where substantial overageing has occurred. The hardness minima position is normally found near the TMAZ/HAZ boundary, and moves in or out depending on the heat input and travel speed $[8,9]$.
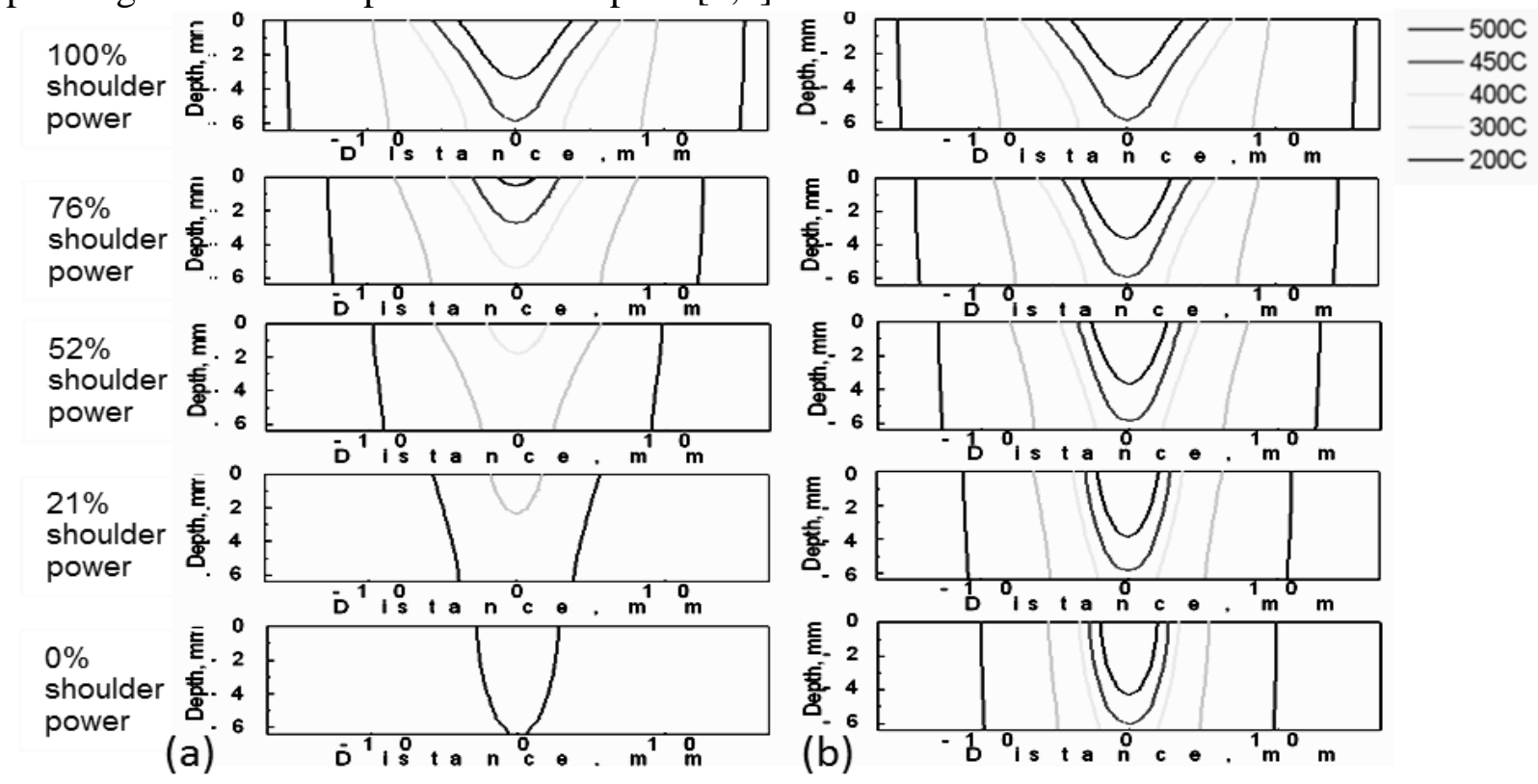

Fig. 4 Thermal modelling depicting the response of the thermal field to reducing the shoulder heat input in FSW; (a) while maintaining a constant probe power and (b) with the probe power increased to maintain a $450^{\circ} \mathrm{C}$ temperature at the base of the weld.
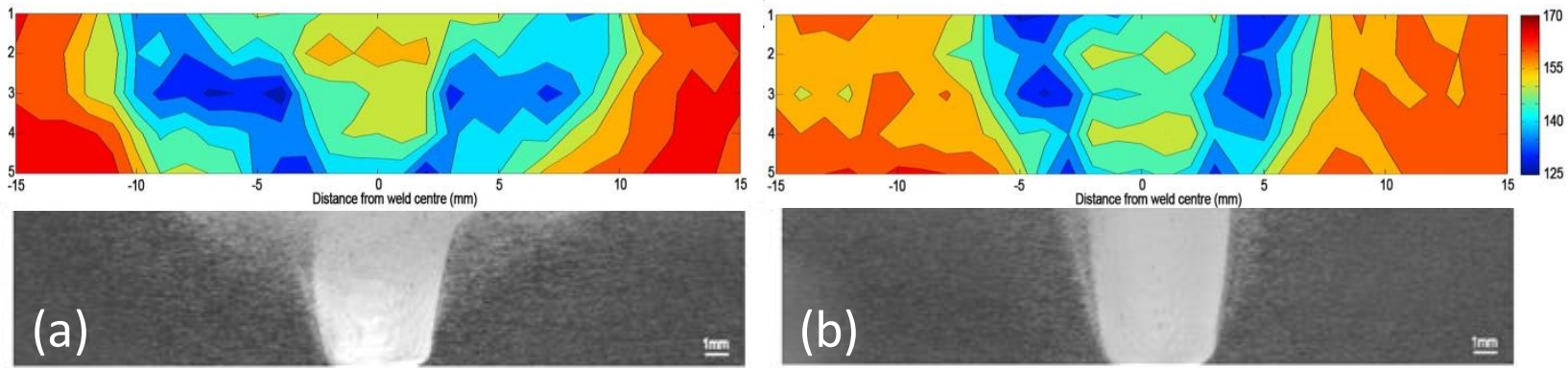

Fig. 5 Cross-section hardness maps for the two processes, when welding under optimum conditions, (a) a FSW tool at $700 \mathrm{rpm}$ and (b) a SS-FSW tool at 1,500 rpm (both at $400 \mathrm{~mm} \mathrm{~min}^{-1}$ ).

In Fig. 5a transverse cross-section 2D hardness maps are shown measured from welds produced with the FSW and SS-FSW tools, under their optimum conditions of 700 and 1500 $\mathrm{rpm}$ at $400 \mathrm{~mm} \mathrm{~min}^{-1}$, respectively. In the case of the standard weld the minimum hardness contour exhibits a classical V shape, due to the majority of the heat input being provided by the tool shoulder. The top of the weld was also clearly much hotter than the base and its hardness has thus recovered more by natural ageing within the weld nugget. In comparison, it can be seen that for the weld produced with the static shoulder the minimum hardness contours are more vertical and at the top the maximum HAZ width is reduced by $40 \%$, because the absence of

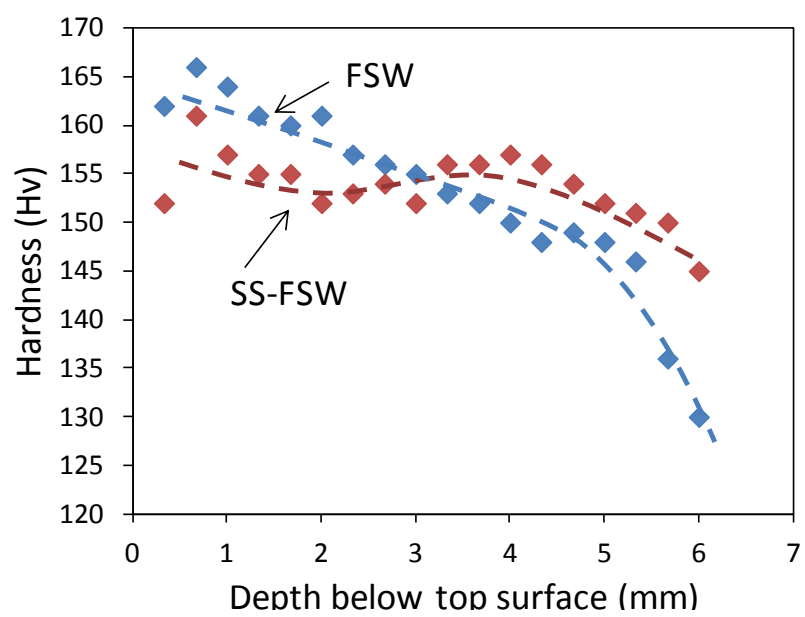

Fig. 6 Through thickness hardness profiles down the centre of the weld nuggets for the two processes, when welding under optimum conditions. 
shoulder rotation, narrows the thermal field at the plate surface. In addition in Fig. 6 it can be seen that the through thickness hardness gradient down the centre of the weld nugget is greatly reduced for the case of the SS-FSW, because when the heat input is generated solely by the pin this leads to a much more uniform though thickness temperature distribution. The typical weld hardness profiles for the two processes thus follow closely the behaviour expected from the thermal simulations in Fig. 4.

\section{Conclusions}

A systematic study has been performed to compare welds produced in an AA7050 alloy by FSW with SS-FSW, when both processes are used under optimum conditions. It has been shown that at identical translation rates to the conventional process SS-FSW can produce welds with a lower heat input, which are more uniform through thickness, and have an exceptional surface finish. In addition the welds show little reduction in section thickness, and have a narrower weld zone profile, which results from a reduced HAZ width, and have more uniform through thickness properties. Analogous to in laser welding, thermal simulations have shown that these benefits arise from changing the process from one where the majority of heat is introduced by surface conduction to one where heat is provided via a keyhole. This improvement is expected to be obtained across all sections thicker than that studied where the role of the heat generated by the shoulder becomes increasingly irrelevant.

Acknowledgements: We are grateful for financial support provided by EPSRC through LATEST2, (EP/G022402/1) and the Metallic Systems CDT (EP/G036950/1).

\section{References}

[1] P. L. Threadgill1, A. J. Leonard, H. R. Shercliff and P. J. Withers, Friction stir welding of aluminium alloys, Int. Materials Reviews 54 (2009) 49-93.

[2] M.J. Russell, M.E. Nunn, J. Martin, Recent developments in the stationary shoulder FSW of Titanium alloys, 7th Int. Symp. on Friction Stir Welding, Japan, 2008, pub. TWI, 10B.

[3] M.M.Z. Ahmed, B.P. Wynne, W.M. Rainforth and P.L. Threadgill, Through-thickness crystallographic texture of stationary shoulder FSW aluminium, Scripta Mater. 64 (2011) 45-48.

[4] H Schmidt, J Hattel and J Wert, Analytical model for the heat generation in friction stir welding, Modelling Simul. Mater. Sci. Eng. 12 (2004) 143-157.

[5] T. Long, W. Tang and A. P. Reynolds, Process response parameter relationships in aluminium alloy friction stir welds, Sci. Technol. Welding and Joining 12 (2007) 311-37.

[6] S. Cui, Z.W. Chen, J.D. Robson, A model relating tool torque and its associated power to rotation and forward speeds during FSW, Int. J. Machine Tools \& Manu. 50 (2010) 1023-1030.

[7] Z. Peng and T. Sheppard, Study of surface cracking during extrusion of aluminium alloy AA 2014, Mater. Sci and Technol. 20 (2004) 1179-1191

[8] Kh. A.A. Hassan, P.B. Prangnell, A.F. Norman, D.A. Price, and S.W. Williams, The Effect of Welding Parameters on the Nugget Zone Microstructure and Properties in High Strength AlAlloy Friction Stir Welds, Sci. \& Tech. of Welding and Joining, 8 (2003) 257-268.

[9] N. Kamp, A. Sullivan, R. Tomasi, J.D. Robson, Modelling of heterogeneous precipitate distribution evolution during friction stir welding process, Acta Materialia 54 (2006) 20032014. 